\title{
DESIGN AND DEVELOPMENT OF SOLAR CROP
}

\section{DRYER INTEGRATED WITH OIL BATH}

\section{PREMKUMAR. $\mathrm{S}^{1,2}$, RAMANARASIMHA. $\mathrm{K}^{3}$ \& E. S. PRAKASH ${ }^{4}$}

${ }^{I}$ Department of Mechanical Engineering, SDMIT, Ujire, Karnataka, India

${ }^{2}$ Research Scholar, Department of Mechanical Engineering, VTU, Belagavi, Karnataka India

${ }^{3}$ Department of Mechanical Engineering, KSIT, Bengaluru, Karnataka, India

${ }^{4}$ Department of Mechanical Engineering, UBDTCE, Davanagere, Karnataka, India

\section{ABSTRACT}

Solar drying is one of the important applications of solar energy used for crop drying applications. In this study, an oil bath has been integrated with solar dryer and experimental work has been conducted and analysis is made for the performance. The design and fabrication details of the developed dryer system are explained. The main objective of this study is to improve the performance of solar dryer by using an oil bath for the collection and storage of sun's energy. The use of oil bath helps to avoid sudden fluctuations in the air temperature inside the dryer. The relative humidity of incoming atmospheric air decreases when passes through the oil bath, and this enables to remove more amount moisture from the product to be dry. The crops used during the experiments were potato slices (2 $\mathrm{kg})$ and ginger (2 Kg) and the air velocity maintained was $10 \mathrm{~m} / \mathrm{s}$. Potato slices of upper and lower tray have taken the drying time of 5 hours and 6 hour to reach safe storage moisture content of below $15 \%$ whereas, ginger of upper tray and lower tray have taken drying time of 9 hours and 10 hours to reach moisture content of below 15. The maximum value of instantaneous of the collector (Oil bath) efficiency reported was $57.48 \%$ and minimum value was $18.59 \%$.

KEYWORDS: Solar Energy, Solar Drying, Mixed Mode Dryer, Crop Drying \& Heat Storage

Received: Jan 16, 2019; Accepted: Feb 06, 2019; Published: Mar 01, 2019; Paper Id.: IJMPERDAPR201936

\section{INTRODUCTION}

The world's requirement of food products has been increasing due to population explosion and the people's change in eating habits, therefore to meet the food products requirement of the world's population is a major challenge. In developed countries, advanced technologies are adopted in production and storage of food product, whereas in developing countries due to lack of modern technologies in the field of food products production and storage, providing food security is a major problem, and it is an immediate requirement to develop low cost techniques to increase the food production rate, reduce the harvesting losses and to minimise storage losses. Food and Agricultural Organisation of United States estimated that, loss of post harvesting food products is high in developing countries and the yearly food loss by quantity estimated is around 30 percent of cereals, $40-50$ percent of root crops, fruits and vegetables, 20 percent of oilseeds, meat and dairy products, and 35 percent of fish [1]. To produce food products, it is required to consume resources like fresh water, agricultural land, fertiliser, pesticides, human work and mechanical energy and therefore, loss of food products affects the waste of all these resources [2]. If technologies are developed to reduce the loss of food products, it indirectly saves other resources and helps to achieve food security. Solar drying is one of the applications of solar energy that can be used to reduce 
loss of food products. Solar drying is a simple method and sun's energy is available at free of cost and, therefore solar drying is best suitable for developing countries, where sufficient cold storage facilities are not available for food products storage. Common crop drying method practised from ancient time is by spreading product to be dried over a platform or plane surface and product is directly exposed to the rays of sun, moisture evaporation takes place due to heat of sun's rays and due to flow of atmospheric air over the product surface. This method of drying is called as open sun drying or natural drying. The open sun drying is a simple and economical method but it suffers from lot of disadvantages like no control over the drying rate, attack by birds and animals, dust and other particles may mix with the product, sudden rain may cause damage [3] and long drying time of a crop with direct ultraviolet light may degrade valuable photochemical [4]. To overcome the disadvantages of open sun drying, solar dryers are developed. Solar dryers are mainly three type's namely direct mode solar dryers, indirect mode solar dryers and mixed mode solar dryers. In direct mode solar dryers, solar radiation is allowed directly to incident on the product to be dried, whereas in indirect mode dryers, air is heated by a solar collector (air heater) and then allowed flow through a closed drying chamber and mixed mode dryers employs the features of both direct mode and indirect mode dryers. Food crops are diversified in their properties, so selection of dryer depends on the different parameters, like Physical features of dryer, Thermal performance, being handled, Drying characteristics of the Material, Flow of material to and from the dryer, Product qualities, Facilities available at site of proposed installation and Economics

People of technical and scientific community around the world have developed different types of solar crop dryers. Prior to design of any dryer, it is very essential to understand the drying phenomenon of crops under open sun drying conditions, Jain and Thiwari [5] studied and discussed many thermal aspects of open sun drying of various crops like green chillies, green pea, onions, potatoes, and cauliflower and it reported that, the convective heat transfer coefficient for varied significantly with type of crop. This is mainly due to porosity, shape, size and initial moisture contents of the crops are different. Therefore, process of drying characteristic is not same for all crops and it is depends on properties of crop. Construction of solar dryers is an easy process, because most of crops not demands higher temperature and for a instance preferred drying temperature for Corn is $68{ }^{\circ} \mathrm{C}-80{ }^{\circ} \mathrm{C}$, Bananas is $70{ }^{\circ} \mathrm{C}$. Researcher [6] designed a solar grain dryer for domestic applications by using locally available materials such as, plywood, perplex glass, wire mesh angle iron and similar type of simple direct mode dryers were also invented for drying of yam crop [7], fishery products [8] and tropical crops [9].

For photosensitive crops, it is not desirable to expose crop directly to Sun's rays because direct explosion causes loss of nutritious contents from the crops and for photosensitive crops indirect mode dryers are best suitable. Researchers have developed indirect mode drying systems by using different materials to collect solar energy to heat the incoming atmospheric air. Some of the important materials used were gravels for chillies drying [10], vacuum tube collectors were used for drying of chillies [11], sand bed was also used to collect heat energy from the sun [12] and phase change materials were also reported for drying grapes [13].

As mentioned in the earlier section, mixed mode dryers employs the principle of both direct and indirect modes of dryers and it is observed in the literature that, researchers around the world have proposed their concepts mixed mode dryers for crop drying. A mixed mode dryer for drying of Yam's chips have been developed by using $2 \mathrm{~mm}$ aluminium sheet for absorber material and well-seasoned wood for cabin material [14]. Similar dryer type of dryer with iron sheet as the absorber material was proposed for the drying of Cuminum grains [15]. Some researchers were tried to improve the 
performance of dryers by using simple techniques like pebbles (heat storage material) coated with black [16]. Recent mixed mode solar crop dryers developed with sensible heat storage materials are; pebbles as heat storage material for drying of chillies [17], pebbles with black coating for drying of chillies [18].

Apart from the conventional research work on dryers, some typical category of dryers were also developed, and one such dryer developed was cylindrical glass drying section chamber developed and a flat plate collector (Air heater) made of galvanised steel sheet as absorber) was used [19] and the advantage is, cylindrical glass drying chamber receives sun's rays from all the directions without any tracking mechanism. Mathematical and numerical model analysis to understand drying phenomenon were also carried out for the drying models of cylindrical tunnel type [20], direct mode, indirect mode and mixed mode type of dryers [21].

In this work, a mixed mode solar crop dryer was designed for agricultural crop drying. Used SAE 20/40 lubricating oil from the automobiles was used to collect solar energy by means of oil bath.

\section{MATERIALS AND METHODOLOGY}

\subsection{Selection of Oil for Heat Storage}

Large quantity of lubricating oil is used in the vehicles to reduce the friction between the moving parts. Lubricating oil absorbs heat released due to friction between moving parts and lubricating oil produces a thin oil film between the moving parts. Lubricating oil loses its properties during the engine operation over a period of time, and then it is replaced by new engine oil. It is observed that in many local small vehicle service stations, during the process of refilling, the drained lubricating oil from engines is not collected properly and it is not sending to recycling process. The common method practiced in local vehicles service stations to dispose the drained engine oil is by direct burning, this is a waste valuable resource. This wastage can be reduced by incorporating with solar dryers, because the solar dryers are decentralised type of systems and can be used wherever sun's energy is available.

The drained SAE20/40 engine oil from a local vehicle service station was collected and flash and fire points were found by using Cleveland open cup apparatus. The flash fire point for fresh SAE 20/40 oil was observed at $224{ }^{\circ} \mathrm{C}$ and 245 ${ }^{0} \mathrm{C}$, whereas for the drained SAE $20 / 40$ oil the flash point was $120{ }^{\circ} \mathrm{C}$ and the fire point was $140{ }^{\circ} \mathrm{C}$. It is observed that, the flash and fire points of used lubricating oil drops down, this is because during the engine operation the lubricating oil is subjected to repeated heating and cooling, and this leads to weaken the chemical bonds, and therefore oil loses its property to form a thin film between moving parts.

Higher drying temperature is not preferable for crop drying, because crop loses germinating property at higher temperatures and possibility of losing some important nutrients. For most of the crops, drying temperature required is not high temperature, and it is in the ranges from $40^{\circ} \mathrm{C}$ to $80^{\circ} \mathrm{C}$. The required moderate temperature of crop drying is achievable by economically available sensible heat storage materials. In this work, an attempt is made to use drained engine oil for solar drying applications.

\subsection{Design and Fabrication of Experimental Setup}

As earlier quoted in the introduction part, selection of dryer is bound by number of parameters and accurate design procedures have been not developed. In this work, the drying chamber and heat storage material (Oil bath) casing dimensions were selected by keeping length to width ratio as 1.5 , length and width of both heat storage casing and dryer 
dimensions were maintained identical [22]. This dryer have been developed to remove the moisture from crops in all seasons, and therefore annual optimisation of slope have been followed i. e. slope is equal to latitude of the test location [23].

The complete experimental setup was fabricated by using low cost materials available at local market, galvanised iron sheet of $0.5 \mathrm{~mm}$ thickness is used to develop oil bath and drying chambers and transparent glass cover of $5 \mathrm{~mm}$ thickness is used to reduce reradiating losses and to maximise the rate solar energy collection, inside exposed surfaces of both the chambers are coated with black. Insulation at all sides of both the chambers is provided with thermocoal. A spiral aluminium tube is immersed in the oil bath and inlet is connected with air blower and outlet is connected to a drying chamber. At the top, ventilating facility had provided. Two Iron mesh trays were used to keep the products to be dried. The care had taken for air gaps and other leakages. The complete experimental setup is fixed towards south direction. India is located in northern hemisphere of the earth. The sun in winter rises in south east and sets in south west. The collector for all locations in India should be oriented in a direction facing south [24], therefore the fabricated experimental setup was fixed towards south direction. The schematic diagram of experimental is shown by the figure 2.1 and Figure 2.2 represents the pictorial view of experimental setup.

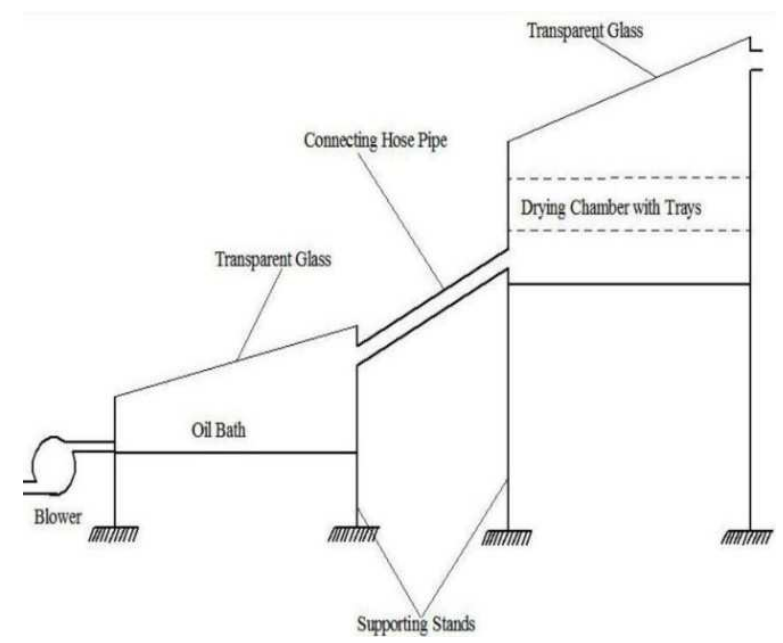

Figure 2.1: Shematic diagram of Expermental Setup

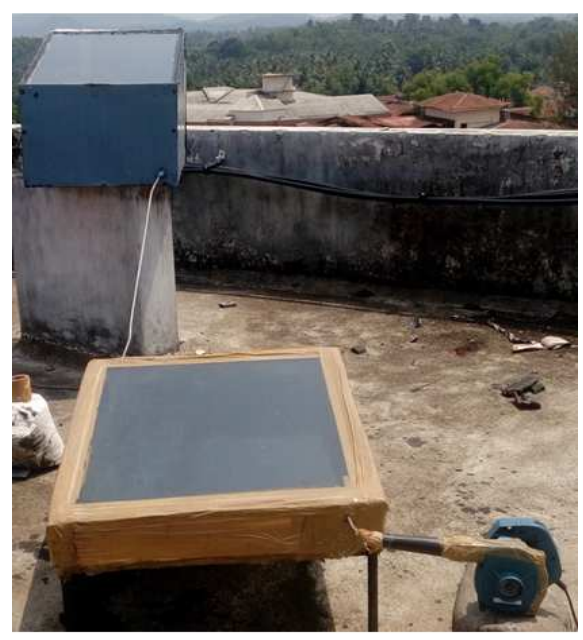

Figure 2.2: Pictorial diagram of Experimental Setup 
Preliminary experiments on oil bath chamber were conducted to find optimum air velocity and optimum oil depth, the optimum velocity obtained was $10 \mathrm{~m} / \mathrm{s}$ and optimum oil bath depth was $60 \mathrm{~mm}$.

\subsection{Experimental Procedure}

Products used during the experiments were potato slices and ginger. In the first set of experiments, $4 \mathrm{~kg}$ of potatoes slices were placed on two trays of the dryer and experiments were started at 9:00 am and stopped when the potato slices reaches the safe moisture content level, and the same procedure was repeated for drying of ginger. The maximum percentage of moisture content for safe storage recommended is below 20 percent for fruits, below 10 percent for vegetables and 10 to 15 percent for grains [25]. Potato slices and ginger were used in this study and they are vegetables, so below 15 percentage of moisture content was taken safe moisture content during the experiments. For every one hour interval, steady state readings were taken, calibrated digital weighing machine was used to measure weight of the product, calibrated thermometers were used to measure temperate at different locations of the experimental setup and pyranometer was used to measure intensity of solar radiation.

\subsection{Performance Analysis}

\subsubsection{Determination of Overall Thermal Efficiency of the Dryer}

To find the thermal efficiency of solar collectors, two methods are used; the instantaneous method and the calorimetric method. For testing of solar collectors, instantaneous method is widely used [26]. The equation (1) represents the thermal efficiency of solar collector by instantaneous method.

$$
\eta_{H}=\frac{\operatorname{ma~Cp}(\mathrm{T} 2-\mathrm{T} 1)}{\mathrm{Ic} A+W P}
$$

In equation (1), $\mathrm{m}_{\mathrm{a}}$ is mass flow rate of air in $\mathrm{kg} / \mathrm{s}, \mathrm{C}_{\mathrm{p}}$ is specific heat of air in $\mathrm{J} / \mathrm{kgK}, \mathrm{T}_{1}$ and $\mathrm{T}_{2}$ are air inlet and outlet temperatures in ${ }^{0} \mathrm{C}, \mathrm{I}_{\mathrm{c}}$ intensity of solar radiation in $\mathrm{W} / \mathrm{m}^{2}$, A is gross area of heat storage cabin in $\mathrm{m}^{2}$ and $\mathrm{W}_{\mathrm{P}}$ is power required for blower.

\subsubsection{Determination of Moisture Content}

To find the moisture content of a product, two methods are used; wet basis method and dry basis method. Most of the researchers have been using wet basis method. The equation (2) gives correlation to calculate moisture content based on wet basis.

$$
\mathrm{M}_{\mathrm{WB}}=\frac{(\mathrm{W}-\mathrm{Wd})}{\mathrm{W}} \times 100
$$

In equation (2), $\mathrm{W}_{\mathrm{WB}}$ is moisture content, $\mathrm{W}$ is weight at any given drying period and $\mathrm{W}_{\mathrm{d}}$ is dry bone weight. Electric oven method is used to find dry bone weight of the product.

\subsubsection{Determination of Drying Rate}

Drying rate is the amount of moisture evaporated from a product for given drying time. Equation(3) represents the rate of moisture evaporated.

$$
\mathrm{DR}=\frac{\mathrm{dm}}{\mathrm{dt}}
$$

In equation (3), $\mathrm{dm}$ is difference in weight and $\mathrm{dt}$ is time period. 


\subsubsection{Determination of Heat Energy Used}

The heat energy used to evaporate the moisture from a product is calculated by using equation (4)

$\mathrm{Q}=\left(\mathrm{W}_{0}-\mathrm{W}\right) \mathrm{h}_{\mathrm{fg}}$

In equation (4) $\mathrm{W}_{0}$ is initial weight of the product, $\mathrm{W}$ is the final weight of the product and $\mathrm{h}_{\mathrm{fg}}$ is latent heat of vaporization of water.

\subsubsection{Determination of Relative Humidity $(\Phi)$}

Relative humidity is the ratio the mass of water vapour to the mass of saturated water vapour in the same volume at the same temperature. The correlations (5) and (6) are used to find the relative humidity.

$$
\begin{aligned}
& \mathrm{Pv}=(\mathrm{Pvs})_{\mathrm{WBT}}-\frac{(\mathrm{P}-(\mathrm{Pvs}) \mathrm{WBT})-(\mathrm{DBT}-\mathrm{WBT})}{1427-1.44 \mathrm{WBT}} \\
& \Phi=\frac{\mathrm{Pv}}{\mathrm{PVS}}
\end{aligned}
$$

\section{RESULTS AND DISCUSSIONS}

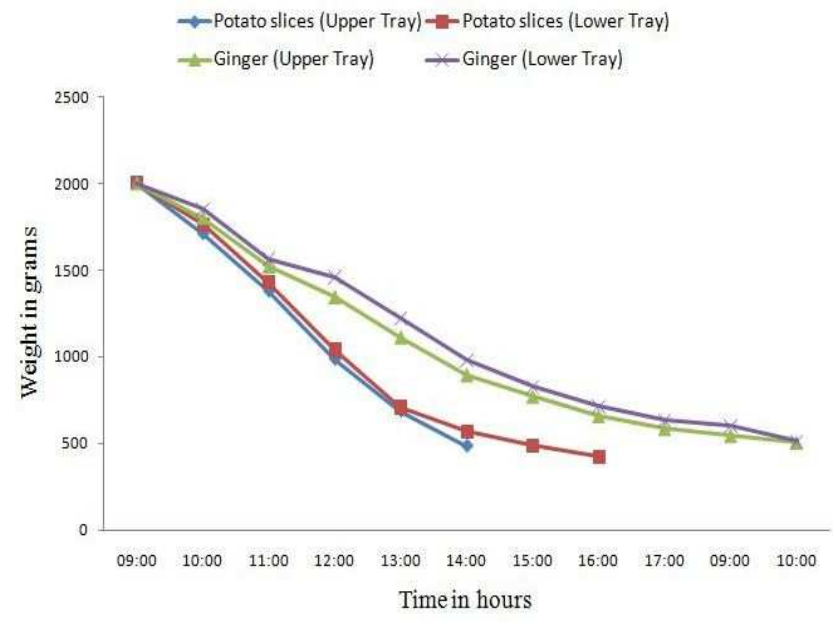

Figure 3.1. Drying Time V/S Product Weight

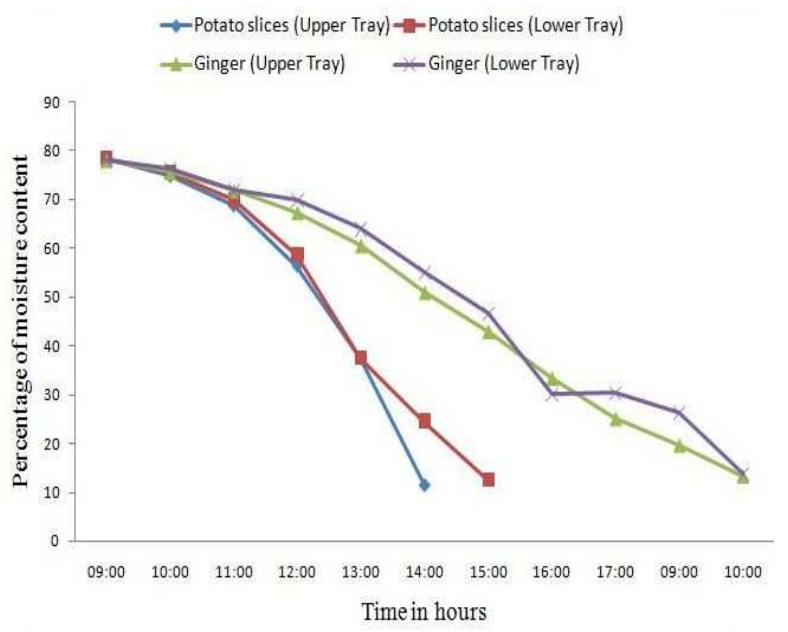

Figure 3.2: Drying Time v/s Percentage of Moisture Content 

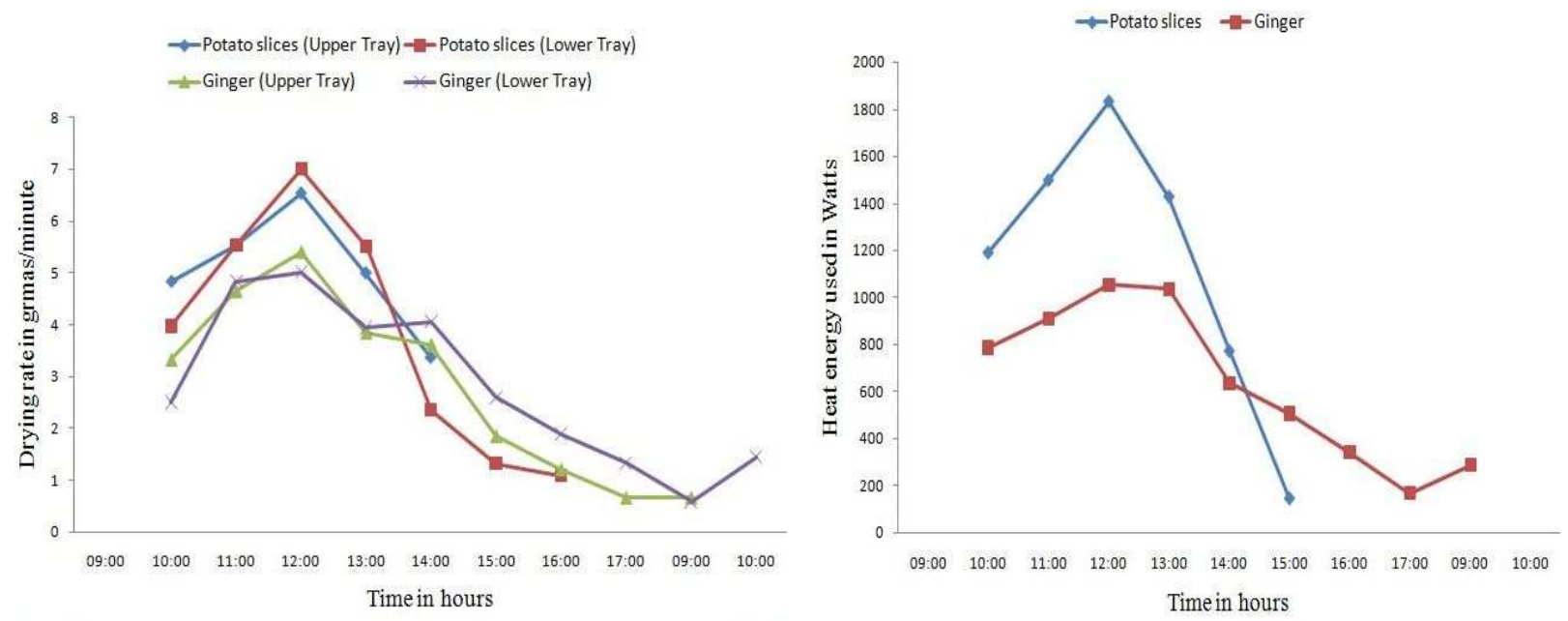

Figure 3.3: Drying Time v/s Drying Rate

Figure 3.4: Drying Time v/s Heat Energy Used

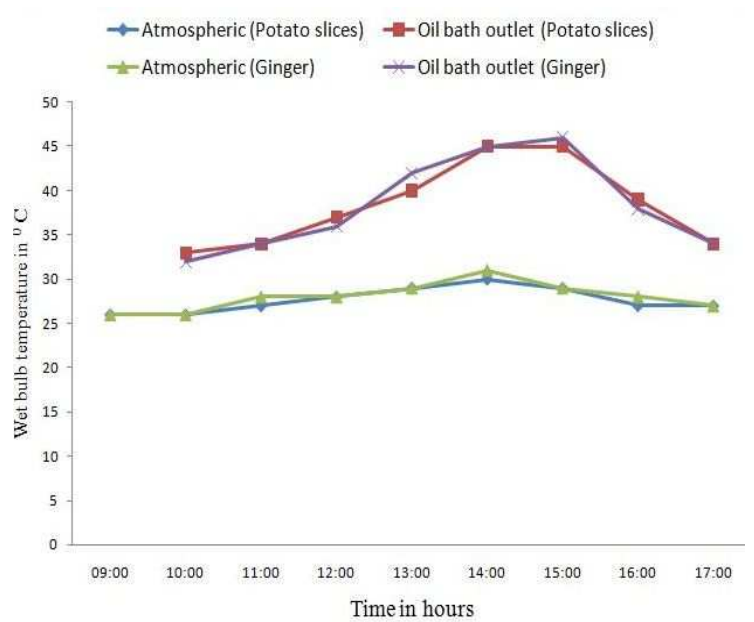

Figure 3.5: Drying Time V/S Wet Bulb Temperature

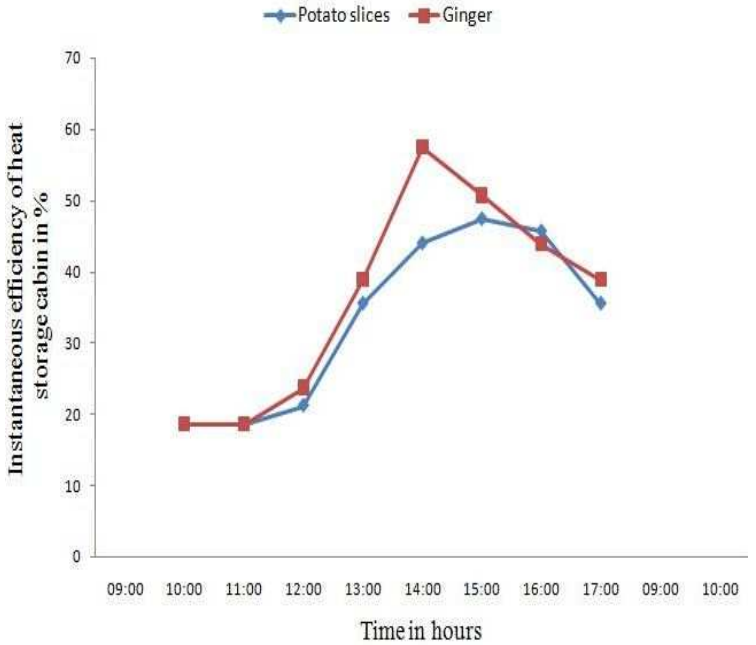

Figure 3.6: Drying Time V/S Instanatneous Effiency of the Heat Storage Cabin

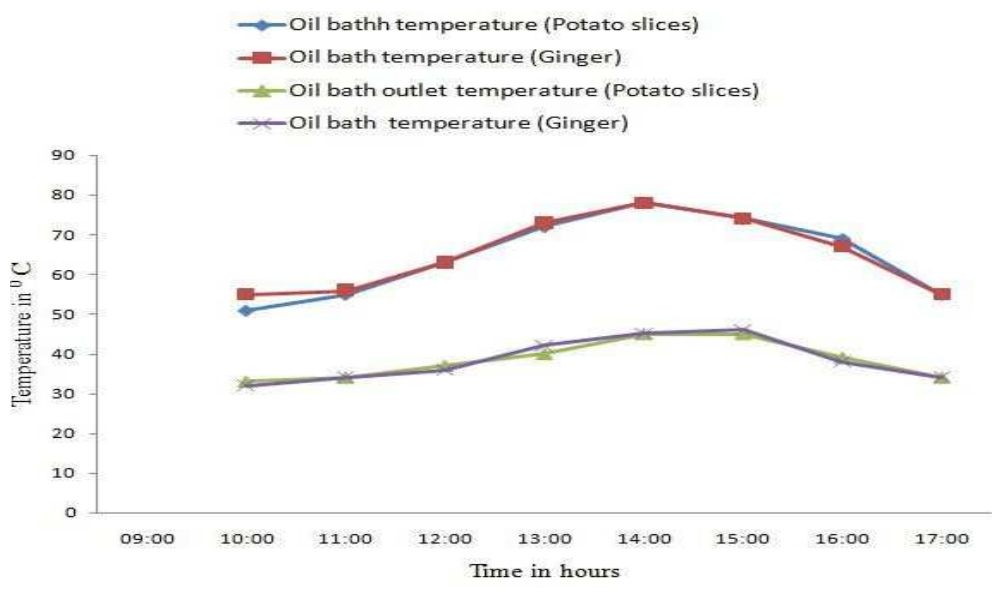

Figure 3.7: Drying Temperature V/S Temperature 


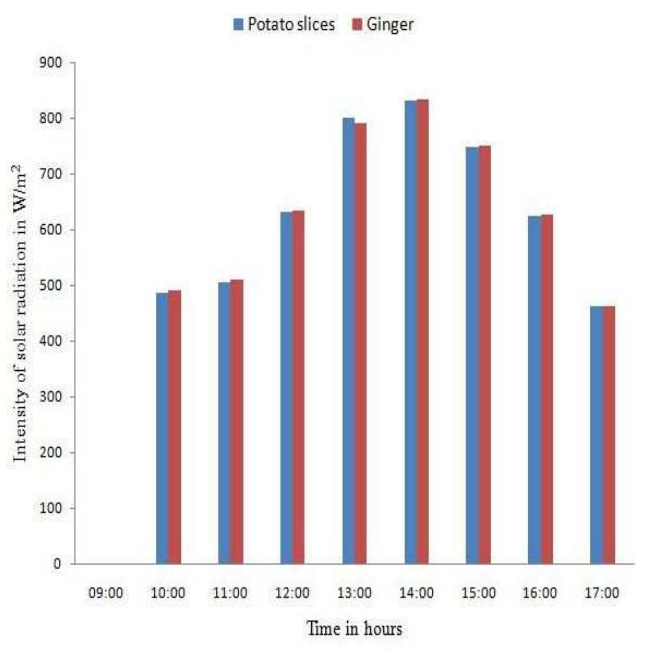

Figure 3.8: Drying Time V/S Intensity of Solar Radiation

In this section, obtained results are discussed with the help of performance curves drawn. The figure 3.1 represents the performance curve of drying time weight of the product. It is observed that, the product of upper trays loses more amount of water content than the products of lower trays. This is because, products of upper tray receives direct sun's radiation and on the products of lower trays, shading effect of upper trays is always present, and this shading effect causes to receive less amount of sun's heat for moisture evaporation. Figure 3.2 represents the drying time against percentage of moisture content of the product on wet basis. As mentioned in the section 2.1, for vegetables and fruits recommended moisture content of the product is below 15 percent. Moisture present in the vegetables and fruits is of two types; bound moisture and unbound moisture. Bound moisture of the product is not possible to remove because of cells arrangement and unbound moisture is possible to separate from the product during the drying process. The potato slices have the initial moisture content of $78.5 \%$ and ginger has $78 \%$. In the initial drying time between 9:00 hour to 10:00 hour, both potato slices and ginger have shown almost equal percentage of decrease in their moisture content and after this duration, deviation in the percentage of moisture decreased has been observed and this is due to fact that during the period of initial drying, more amount of moisture is available in the product at outer surfaces and therefore, percentage of moisture decreased is almost same for both potato slices and ginger. As the drying process progresses, the percentage of moisture content decreased is high for potato slices than the ginger. In the potato slices, the surface structure is made of less number of fibres, whereas in the ginger surface, structure is made of more number of small fibres and this structure causes obstacle to the water to flow from inner surfaces to the outer surfaces to get evaporate. Therefore, structure of the material plays an important role in the drying process. The potato slices at upper trays requires a drying time of 5 hours to reach safe storage moisture content, potato slices at lower tray requires 6 hour drying time to attain safe storage moisture content. The ginger at upper tray takes 9 hours of drying and ginger at lower tray takes 10 hour of drying to reach the safe moisture content. The moisture evaporation for a given time period is called drying rate. The figure 3.3 represents curves of drying time against drying rate and it has observe that, during the initial periods drying the drying rate increases linearly with drying time and attains a maximum drying rate. The maxim drying rates observed for potato slices is 6.99 grams/minute (Upper tray) and 6.5 grams/min (Lower tray), similarly for ginger maximum drying reported are 3.8 grams/minute (Upper tray) and 4.08 grams/minute (Lower tray). During the periods of initial drying, more amount of water is available at outer surfaces and therefore drying rates increases linearly with drying time and after reaching maximum value of drying rate, the amount of water present in the product is less and therefore drying rate decreases sharply and at the end periods of 
drying, the products contains less amount of unbound moisture, therefore drying rate becomes almost constant. The heat energy of sun's radiation is a main reason to evaporate moisture from the product, so more amount of moisture is possible to remove from the products, if the rate of heat transfer to the product is high. It is observed from the figure 3.4 that, the rate of heat energy used for drying of potato slices is more as compared the rate of heat energy used for ginger drying. This is because, potato slices having large surface area for heat transfer, whereas the surface area available for heat transfer is comparatively less in ginger drying. Figure 3.5 represents the variation of wet bulb temperature (WBT) with drying time. It has been observe that, atmospheric air WBT has increased significantly after passing through oil bath and the increase in WBT decreases the relative humidity of the air, and thus water carrying capacity of air increases. The variation of atmospheric WBT and oil bath outlet WBT is almost same and this results in more accuracy in the analysis. The variation in the instantaneous efficiency of heat storage cabin is shown by the figure 3.6. The nature of variation in the efficiency is same during the drying potato slices and ginger. During the initial periods, efficiency is same and after the initial period, efficiency increases and reaches the maximum value and start decreasing. The maximum efficiency reported is $57.48 \%$ and minimum is $18.59 \%$. The variation of oil bath temperature and outlet air temperature of oil bath is given by the figure 3.7. The temperature of oil bath is always at higher temperature than the outlet air temperature of air from the oil bath. The tube used during the experiment was aluminium tube and practically for any system, it is not possible to transfer heat completely. The rate heat transfer can be increased by using the tube which is having better thermal conductivity, but tubes with high thermal conductivity are costly and this increases the total cost of the system. The efficiency of oil bath is influenced by amount of sun's radiation available. A day with good sunshine hours helps to get better efficiency. The maximum oil bath temperature reported is $78^{\circ} \mathrm{C}$ and minimum temperature is $51{ }^{\circ} \mathrm{C}$ and at the outlet of oil bath the maximum and minimum air temperature reported is $66{ }^{\circ} \mathrm{C}$ and $41{ }^{\circ} \mathrm{C}$. The required amount of heat energy for product drying is by sun's radiation and intensity of incident solar radiation affects the process of drying. In a day with sky free from clouds receives high rate of sun's energy as compared to a day with clouds. During the experiments, sky was free from clouds and the maximum amount of radiation had received. The figure 3.8 shows the variation in solar radiation intensity with drying time. It is observe that, the received amounts of solar radiation during the experimental time are very close to each other, and hence uncertainty is not considered for the analysis. The maximum value of solar radiation received is $833 \mathrm{~W} / \mathrm{m}^{2}$ and minimum is $463 \mathrm{~W} / \mathrm{m}^{2}$

\section{CONCLUSIONS}

The present work explains the design, fabrication and experimental analysis of a solar drying system integrated with oil bath. The substance used for collecting heat was used SAE 20/30 engine oil. The food products used during the experiments were potato slices and ginger. The use of oil bath enables to collect solar energy in the form of heat and helps to avoid sudden variation in the dryer temperature due environmental interruptions. Potato slices of upper and lower tray have taken the drying time of 5 hours and 6 hour to reach safe storage moisture content of below $15 \%$ and whereas, ginger of upper tray and lower tray have taken drying time of 9 hours and 10 hours to reach moisture content of below $15 \%$. The internal structure of material affects process of moisture evaporation during the drying process. Products with an internal structure with less number of fibres shows better drying rates as compared to product with internal structure made of large numbers of fibre. The surface area of product, which is exposed to the current of hot air stream, affects the process of drying. The maximum value of instantaneous efficiency reported was $57.48 \%$ and minimum value was $18.59 \%$. 


\section{REFERENCES}

1. Global Initiative on Food Loss and Waste Reduction (2015), Food and agricultural organization of United Nations

2. М. Китти, et al., Lost food, wasted resources: Global food supply chain losses and their impacts on freshwater, cropland, and fertiliser use, Science of the Total Environment 438 (2012) 477-489, Elsevier.

3. P Garg and J Prakash, Solar Energy, 1st Revised ed. TATA McGraw-Hill Publishing Company Limited, New Delhi,. Page 119

4. Visavale, G. L., Principles, Classification and Selection of Solar Dryers. In Solar drying: Fundamentals, Applications and Innovations, Ed. Hii, C. L., Ong, S. P., Jangam, S. V. and Mujumdar, A. S., 2012, ISBN-978-981-07-3336-0, Published in Singapore, pp. 1-50.

5. D. Jain and G. N. Tiwari, Thermal aspects of open sun drying of various crops, Centre of energy studies, Indian Institute of Technology, New Delhi Search

6. B. A. Ezekoye and O. M. Enebe, Development and performance Evaluation of Modified Integrated Passive Solar Grain Dryer, The Pacific Journal of Science and Technology, Vol-7, No-2.

7. A. F. Aloge and R. O. Hammed, A direct passive solar dryer for tropical crops, African Crop Science Conference, Vol. 8. pp. 1643-1646.

8. S. H. Senger et al, Low Cost Solar Dryer for Fish, African Journal of Environmental Science and Technology, Vol-3, PP.265271.

9. EHL. P et al, Post Harvesting of Selected Tropical Crops Using a Natural Circulation Solar Dryer, Agricultural Tropical Subtropical, Vol-43 (2) 2010.

10. M. Mohanraj and P. Chandrashekhar, performance of a forced convection solar Drier integrated with gravel as heat storage Material for chilli drying, Journal of Engineering Science and Technology Vol. 4, No. 3 (2009) 305 - 314, School of Engineering, Taylor's University College

11. A. R. Umayal Sundari, et al, Performance of Evacuated Tube Collector Solar Dryer with and Without Heat Sources, Iranica Journal of Energy \& Environment 4 (4): 336-342, 2013, Energy \& Environment 4 (4): 336-342, 2013, ISSN 2079-2115

12. Owaid, A. I., Tariq, M., ISSA, H., Sabeeh, H., \& ALI, M. (2014). The heat losses experimentally in the evacuated tubes solar collector system in baghdad-iraq climate.

13. S. M. Shalaby, Effect of Using Energy Storage Material in an Indirect-mode Forced Convection Solar Dryer on the Drying Characteristics of Grapes, Journal of Medical and Bioengineering (JOMB) Vol. 1, No. 1, September 2012.

14. Mr. Avesahemad Sayyadnaimutulla Husainyl, Prof. P. R. Kulkarni, Performance Analysis Of A Solar Grape Dryer With Thermal Energy Storage by PCM, International Research Journal of Engineering and Technology (IRJET), Volume: 02 Issue: 07, Oct-2015.

15. Bukola O. Bolaji and Ayoola P. Olalusi, Performance Evaluation of a Mixed-Mode Solar Dryer, Technical Report, AU J. T. 11(4): 225-231.

16. Mehdi Moradi and Ali Zomorodian, Thin Layer Solar Drying of Cyminum Grains by Means of Solar Cabinet Dryer, American-Eurasian J, Agric\& Environ. Sci., 5(3): 409-413, 2009

17. Premkumar S et al, Experimental Study on Free and Forced Convective Solar Dryer with Heat Storage Materials" in a National conference on Current Developments and its Applications in Mechanical Engineering (NCCDAME) 10/05/2017 12/05/2017, Page 141-144 at K. S. Institute of Technology, Bengaluru, Karnataka, India. 
18. Premkumar et al, An Experimental Study on Mixed Mode Solar Dryer with Heat Storage Materials, ISSN: 2454-2415 Vol. 6, Issue 6, 2018 June, 2018, PP 124-129.

19. Shanmugan, S. (2014). Experimental analysis of a single slope single basin solar still with hot water provision. International Journal of Applied and Natural Sciences, 3(1), 19-24.

20. S. N. Ugwu et al., Design, construction, and evaluation of a mixed mode solar kiln with black-painted pebble bed for timber seasoning in a tropical setting, RenewableandSustainableEnergyReviews41(2015)1404-1412.

21. Ahmed Abed Gatea, Design and construction of a drying system, a cylindrical section and analysis of the performance of thermal drying system, African journal of Agricultural Research Vol. 6(2), pp. 343-351, 18 January, 2011

22. S. Sadodin, T. T. Kashani, Numerical Investigation of a Solar Tunnel Drier for Drying of Copra, ISESCO JOURNAL of Science and Technology, Vol-7, No. -12 .

23. Bukola Ollalekan Bolaji, Exergetic Analysis of Solar Energy Drying Stsyems, 2011,2 92-97.

24. Francis kofi forson, modelling and experimental Investigation of a mixed-mode Natural convection solar Crop dryer, ph. $d$ thesis De Montfort university, Leicester.

25. Solar energy, S. P. Sukhatme, Second edition, Tata Mcgraw Hill Company Limited, New Delhi, India.

26. User's handbook on solar heaters,, UNDP/GEF Global Solar Water Heating Project, Ministry of New and Renewable Energy, Government of Inda.

27. Kumar, R. S. Latent Heat Storage Material Evaluation Base on AHP and TOPSIS for Low Temperature Solar Heating Applications.

28. Matthew G. Green Dishan Schwaez, Solar Drying Technology for Food Preservation, Gate Information Service / gtz, PO Box 5180, 65726 Eschborn, Germany.

29. H. P. Garg, Treatise on Solar Energy, Jhon Wiley, 1892. 
